\title{
Surgical Treatment of Early Gastric Cancer
}

\author{
Sachiyo Nomura Michio Kaminishi
}

Department of Gastrointestinal Surgery, Graduate School of Medicine, University of Tokyo, Tokyo, Japan

\section{Key Words}

Gastric cancer • Endoscopy • Ultrasound, endoscopic

\begin{abstract}
Around half the cases of gastric cancer are found in the early stage in Japan. With an expected good prognosis, many treatment options have been developed to maintain a good quality of life of the patients after the treatment. Gastric cancer is diagnosed with endoscopy, and the depth of invasion is diagnosed with endoscopy and endoscopic ultrasound. One of the new treatments is endoscopic submucosal dissection. Improvements in surgical treatment are minimizing lymph node dissection, reconstruction methods, laparoscopy-assisted surgery, and sentinel node navigation surgery. Minimizing lymph node dissection for early gastric cancer is well described in the Guidelines for Gastric Cancer Treatments. Pylorus-preserving gastrectomy, jejunal interposition, pouch reconstruction, and Roux-en-Y reconstruction after distal gastrectomy are improvements in reconstruction after gastrectomy. More and more surgeons start laparoscopy-assisted gastrectomy with lymph node dissection. Even with these improvements, the 5-year survival of early gastric cancer is more than $90 \%$ in Japan. Further improvements would be possible in the future.
\end{abstract}

Copyright $\odot 2007$ S. Karger AG, Base
(C) 2007 S. Karger AG, Basel

0253-4886/07/0242-0096\$23.50/0

Fax +4161306 1234 E-Mail karger@karger.ch www.karger.com

\section{Introduction}

The definition of early gastric cancer is tumor confined to the mucosal layer or the mucosal and submucosal layer, regardless of lymph node status [1]. In Japan around half the gastric cancers are found in early stages [2]. According to this, many treatment options for early gastric cancer have been developed to maintain the patients' quality of life even after treatment. One of the remarkable changes in treatment is the use of endoscopic submucosal dissection. The condition for this treatment is that the tumor can be dissected under endoscopy and that there are no lymph node metastases. To fulfill this condition, accumulated data on resected gastric cancer status without lymph node metastasis were analyzed. The surgery has also been modified for early gastric cancer. One of the modifications is the extent of lymph node dissection. Laparoscopy-assisted gastrectomy is also a new technique in the treatment of early gastric cancer.

To apply these treatments correctly, the 1st edition of the Guidelines for Gastric Cancer Treatment was published in 2001 [3] and the 2nd edition was published in 2004 [4]. The guidelines are very useful for the application of standard treatment in clinical settings. They divide the treatment methods into a daily clinical category and a clinical research category, which means that there is potential to improve treatment for gastric cancer. In this article, we will discuss the surgical treatment of early gastric cancer as well as the prognosis of the patients.

Sachiyo Nomura

7-3-1 Hongo

Bunkyo-ku, Tokyo 113-8655 (Japan)

Tel. +81 33815 5411, ext. 35144, Fax +81 358009734

E-Mail snomura-gi@umin.ac.jp 
Table 1. Age distribution of resected gastric cancer cases

\begin{tabular}{llllll}
\hline & \multicolumn{3}{l}{ Age, years } & & \\
\cline { 2 - 5 } & $<39$ & $40-59$ & $60-79$ & $>80$ & not specified \\
\hline Total number & $302(3.8 \%)$ & $2,805(35.4 \%)$ & $4,276(53.9 \%)$ & $344(43.4 \%)$ & $207(2.6 \%)$ \\
5 -year survival, \% & 72.4 & 76.1 & 64.8 & 39.7 & 72.1 \\
\hline
\end{tabular}

\section{Epidemiology}

In 2002 , the mortality rate from gastric cancer was around 40 in 100,000 in Japan. In 1998, the age-adjusted disease rate was 60.4 in 100,000 and the age-adjusted mortality rate was 27.3 in 100,000 . Both the age-adjusted disease rate and the age-adjusted mortality rate have gradually decreased. However, without adjustment both rates have not changed due to the increase in higher age groups in the population.

Data on gastric cancers treated in 1991, registered by the Japanese Gastric Cancer Association, were recently published [2]. At that time, endoscopic mucosal dissection was not as common, and most of the tumors were surgically resected with lymph node dissection. The data on 8,851 patients with primary gastric cancer were collected from 113 hospitals, and the data on 7,935 patients could be analyzed. Among the 7,935 cases, 3,871 (48.8\%) tumors were in the early stages, including 2,209 (27.8\% of tumors, $57.1 \%$ of early tumors) mucosal tumors and 1,662 (20.9\%, 42.9\%) submucosal tumors. 5,493 (69.2\%) patients were male and 2,441 (30.8\%) female. The age distribution is shown in table 1 . The incidence of gastric cancer increases after 40 years of age and is highest in the 60 - to 79-year age group. The prognosis of gastric cancer itself does not differ between age groups.

\section{Diagnosis}

Health check-up program is in progress for people over 39 years of age in Japan. In an ordinal health checkup, barium-swallow roentgenoscopy or serum pepsinogen are common. However, more and more people are having endoscopy without barium swallow. The reason for this may be that patients with suspected lesions on barium swallow have to have endoscopy, and they want to finish the examination with one method. Another reason may be that many physicians believe endoscopy is more sensitive than barium swallow.
The diagnosis of gastric cancer is made histologically from tissue biopsied under endoscopy. The depth of invasion is diagnosed using endoscopy and endoscopic ultrasonography. Lymph node metastasis is analyzed with computed tomography, ultrasonography, and endoscopic ultrasonography. Distant metastases are also analyzed with computed tomography.

\section{Endoscopic Treatment}

Endoscopic treatment for early gastric cancer is a new method which started about 10 years ago. The condition for the treatment is a lack of lymph node metastasis. In daily clinical settings, the guidelines define gastric cancer as being confined to the mucosal layer, $<2 \mathrm{~cm}$ in diameter, differentiated histological type, and without ulcer scar.

However, endoscopic submucosal dissection, a new technique which enables the resection of larger lesions, is changing the indication. In our institute, endoscopic submucosal dissection is indicated when the tumor remains in the mucosal layer and is of a differentiated histological type. After dissection, if the tumor is found to be invading the submucosal layer or vein, the patient is recommended to receive additional surgery.

\section{Surgical Treatment}

\section{Guidelines}

The guidelines for early gastric cancer in daily clinical settings and in clinical research are shown in tables 2 and $3[3,4]$. In fact, N2 or N3 early gastric cancer is rarely diagnosed. A mucosal tumor without lymph node metastases and a submucosal tumor of differentiated histological type, $<1.5 \mathrm{~cm}$ in diameter without lymph node metastases, can be operated using minimal lymph node dissection $\mathrm{D} 1+\alpha$. A tumor of $>2.1 \mathrm{~cm}$ in diameter with $\mathrm{N} 1$ lymph node metastases and a tumor with $\mathrm{N} 2$ lymph node 
Table 2. Treatment options by stage for clinical practice

\begin{tabular}{|c|c|c|c|c|}
\hline & N0 (stage IA) & N1 (stage IB) & N2 (stage II) & N3 (stage IV) \\
\hline $\begin{array}{l}\text { Mucosal } \\
\text { cancer T1 }\end{array}$ & $\begin{array}{l}\text { EMR (en bloc resection; differentiated type, } \\
\leq 2.0 \mathrm{~cm} \text { in diameter; depressed type without } \\
\text { ulceration) } \\
\text { Modified surgery A (other than those above) }\end{array}$ & $\begin{array}{l}\text { Modified surgery B } \\
(\leq 2.0 \mathrm{~cm} \text { in diameter }) \\
\text { Standard surgery } \\
(\geq 2.1 \mathrm{~cm} \text { in diameter })\end{array}$ & $\begin{array}{l}\text { Standard } \\
\text { surgery }\end{array}$ & $\begin{array}{l}\text { Extended surgery, palliative operation, } \\
\text { chemotherapy, radiation therapy, } \\
\text { palliative care }\end{array}$ \\
\hline $\begin{array}{l}\text { Submucosal } \\
\text { cancer T1 }\end{array}$ & $\begin{array}{l}\text { Modified surgery A (differentiated type, } \\
\leq 1.5 \mathrm{~cm} \text { in diameter) } \\
\text { Modified surgery B (other than those above) }\end{array}$ & $\begin{array}{l}\text { Modified surgery B } \\
(\leq 2.0 \mathrm{~cm} \text { in diameter }) \\
\text { Standard surgery } \\
(\geq 2.1 \mathrm{~cm} \text { in diameter })\end{array}$ & $\begin{array}{l}\text { Standard } \\
\text { surgery }\end{array}$ & $\begin{array}{l}\text { Extended surgery, palliative operation, } \\
\text { chemotherapy, radiation therapy, } \\
\text { palliative care }\end{array}$ \\
\hline
\end{tabular}

Modified surgery A and B = resection less than standard surgery including omentum-preserving procedure, omission of omento-bursectomy, pylorus-preserving gastrectomy, and vagus-preserving procedure. According to the extent of lymph node dissection, modified surgery is classified into surgery A (D1+ $\alpha$ dissection) and surgery B $(D 1+\beta$ dissec- tion). Dissected lymph nodes for $\alpha$ : No. 7 regardless of the location of lesions, and additionally No. 8a in cases with lesions located in the lower third of the stomach. Dissected lymph nodes for $\beta$ : No. 7, 8a and 9.

Standard surgery $=$ Resection of two thirds of the stomach with D2 dissection. $\mathrm{EMR}=$ Endoscopic mucosal resection.

Table 3. Treatment options according to stage for clinical study

\begin{tabular}{|c|c|c|c|c|}
\hline & N0 (stage IA) & N1 (stage IB) & N2 (stage II) & N3 (stage IV) \\
\hline $\begin{array}{l}\text { Mucosal cancer T1 } \\
(>2.0 \mathrm{~cm})\end{array}$ & $\begin{array}{l}\text { EMR (piecemeal resection) } \\
\text { ESD (submucosal resection) } \\
\text { EMR (laser treatment for } \\
\text { incomplete resection) }\end{array}$ & $\begin{array}{l}\text { Laparoscopy-assisted } \\
\text { gastrectomy }\end{array}$ & - & $\begin{array}{l}\text { Extended surgery (combined resection, dissection) } \\
\text { Reduction surgery } \\
\text { Chemotherapy (systemic or regional) } \\
\text { Hyperthermochemotherapy }\end{array}$ \\
\hline $\begin{array}{l}\text { Submucosal } \\
\text { cancer T1 }\end{array}$ & $\begin{array}{l}\text { Wedge, segmental resection } \\
\text { Laparoscopic wedge gastrectomy } \\
\text { Laparoscopy-assisted gastrectomy }\end{array}$ & $\begin{array}{l}\text { Laparoscopy-assisted } \\
\text { gastrectomy }\end{array}$ & - & $\begin{array}{l}\text { Extended surgery (combined resection, dissection) } \\
\text { Reduction surgery } \\
\text { Chemotherapy (systemic or regional) } \\
\text { Hyperthermochemotherapy }\end{array}$ \\
\hline
\end{tabular}

Extended surgery $($ dissection $)=$ Extended gastrectomy with extended lymphadenectomy.

Extended surgery (combined resection, dissection) = Gastrectomy with combined resection of involved organs and extended lymphadenectomy. $\mathrm{EMR}=$ Endoscopic mucosal resection; ESD = endoscopic submucosal dissection.

metastases require standard operation. Other early gastric cancers with N0 or N1 can be operated using minimal lymph node dissection $\mathrm{D} 1+\beta$.

\section{Reconstruction}

The form of reconstruction after the resection of the stomach is one of the important issues in the treatment of early gastric cancer because of the good prognosis of the patients. Traditionally, Billroth I and Billroth II are common methods of reconstructions after distal gastrectomy. Many surgeons do not prefer Billroth II because of its bile reflux, remnant gastritis, and the high rate of gastric stump cancer. In place of Billroth II, Roux-en-Y reconstruction is now becoming common for reconstruction after distal gastrectomy. Compared to Billroth I, Roux-en-Y has a low rate of remnant gastritis, gastric stump cancer, and anastomotic leakage; however, Rouxen-Y has a higher rate of Roux stasis syndrome, gallbladder stone formation, and needs a longer operation time. No comparison of the clinical data in a large volume randomized control study has been made, but the superiority of Roux-en-Y with regard to less bile reflux and less inflammation in the remnant stomach and its inferiority with regard to the long operation time and long hospital stay have been reported [5].

After total gastrectomy, Roux-en-Y reconstruction and jejunal interposition are the common methods. Jejunal interposition makes foods pass through duodenum but the operation technique is more complicated. A preliminary randomized clinical trial was started about 5 years ago, but no difference was detected among the roughly 200 patients between these two methods. 
Fig. 1. Schematic illustration of pyloruspreserving gastrectomy (PPG). Anastomosis of PPG. The proximal portion of the stomach is resected with a $75-\mathrm{mm}$ linear cutter. the resection is the same as in conventional distal gastrectomy (a). A twolayer primary gastro-gastro anastomosis is performed; that is, the mucosal layer is sutured continuously with 3-0 absorbable monofilament (b). The seromuscular layer is sutured by a knotting suture with 3-0 Vicryl (c). The stomach is placed back into the abdominal cavity (d), and the closed drain is advanced through the Winslow foramen to the left infrahepatic cavity. a

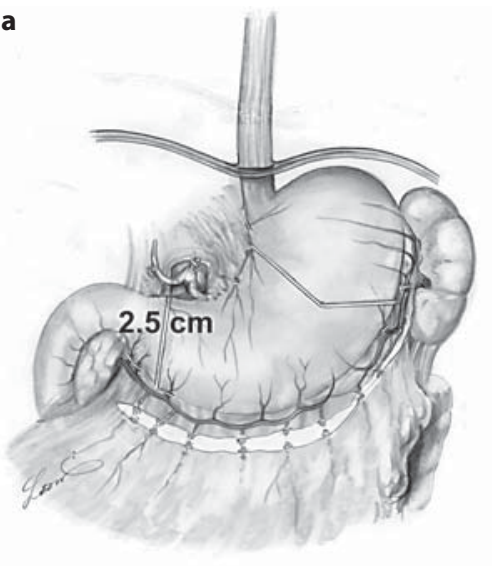

c

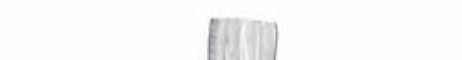

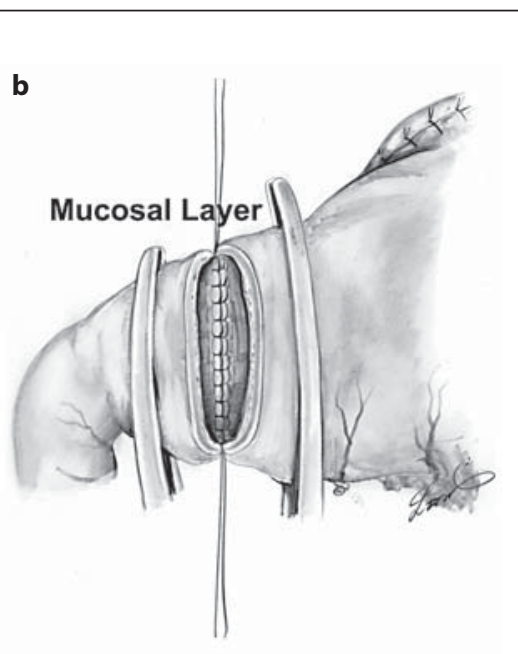

b

d

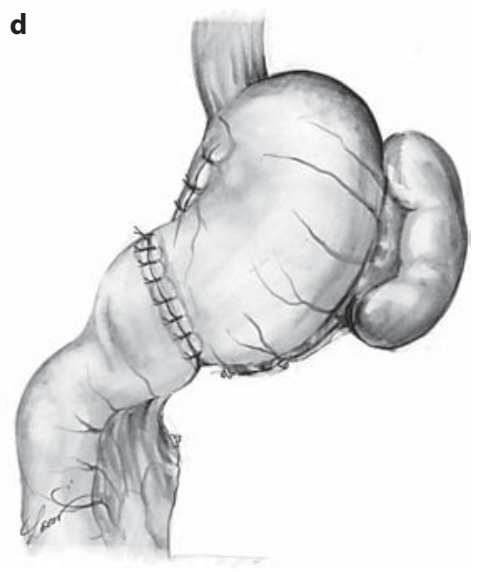

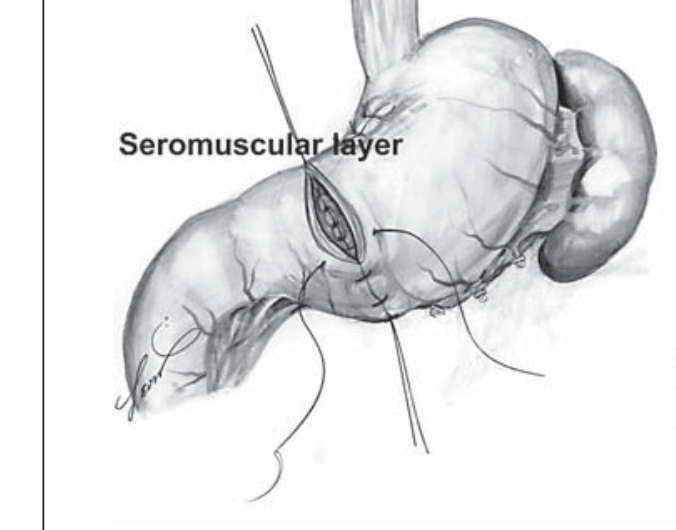

Pouch reconstruction is one of the options for reconstruction after distal gastrectomy, proximal gastrectomy, and total gastrectomy. There are very little data to support pouch reconstruction, and the efficacy of pouch reconstruction has not yet been defined. In our opinion, an evaluation of the quality of life depending on the time course after operation will be needed for the pouch reconstruction $[6,7]$.

Pylorus-preserving gastrectomy (PPG) following gastro-gastro anastomosis can be included in the reconstruction options. PPG is a modification of distal gastrectomy preserving $2-3 \mathrm{~cm}$ of the pyloric cuff which maintains pylorus ring function. The indication of PPG is restricted to tumors with a distance of more than 4.5$5 \mathrm{~cm}$ from the pylorus ring to maintain the distal margin (fig. 1) $[8,9]$. The incidence of early dumping syndrome is reported to be lower in PPG (8\%) than in distal gastrectomy with Billroth I reconstruction (33\%) [10].

\section{Laparoscopy-Assisted Surgery}

Laparoscopy-assisted gastrectomy with lymph node dissection is now one of the modalities for early gastric cancer surgery [11]. The guidelines also define laparoscopy-assisted surgery as a treatment of clinical stage IB cancer. The quality of laparoscopic surgery is reported not to be worse than conventional open laparotomy surgery, and the surgical invasiveness is reported to be less in laparoscopy-assisted surgery $[12,13]$. A new issue in the laparoscopic surgery is the education of younger surgeons.

\section{Sentinel Node Navigation Surgery}

Sentinel node navigation surgery is still under trial for gastric cancer. It is still difficult to detect sentinel nodes and dissect lymph nodes in order to analyze the accuracy of the method. Several reports agree that the indication of sentinel node mapping is early $\mathrm{cN} 0$ tumors $[14,15]$. 
Table 4. Prognosis and recurrent pattern of resected early gastric cancer

\begin{tabular}{|c|c|c|c|c|c|c|c|c|c|c|}
\hline & \multirow{2}{*}{$\begin{array}{l}\text { Total } \\
\text { number }\end{array}$} & \multicolumn{5}{|c|}{ Survival, \%, at } & \multicolumn{4}{|c|}{ Recurrence } \\
\hline & & 1 year & 2 years & 3 years & 4 years & 5 years & local & peritoneal & liver & $\begin{array}{l}\text { distant } \\
\text { metastases }\end{array}$ \\
\hline Mucosa & 2,209 & 98.0 & 96.6 & 95.2 & 94.0 & 92.5 & $6(0.3 \%)$ & $4(0.2 \%)$ & $3(0.1 \%)$ & $2(0.1 \%)$ \\
\hline Submucosa & 1,662 & 96.0 & 93.7 & 90.8 & 89.3 & 87.6 & $17(1.0 \%)$ & $14(0.8 \%)$ & $17(1.0 \%)$ & $7(0.4 \%)$ \\
\hline
\end{tabular}

The detection rate is reported to be $95 \%$, the false-negative rate of lymph node metastasis is $4 \%$, which is still too high to apply sentinel node navigation surgery without lymph node dissection other than the detected sentinel node. Further improvements are needed.

\section{Prognosis}

The Kaplan-Mayer curve is shown in figure 2. The 5 -year survival of early gastric cancer is $90.4 \%$. Recurrent pattern is shown in table 4 . The 5 -year survival of stage IA gastric cancer is $93.4 \%$, and that of stage IB is $87.0 \%$. Comparing these data, adjuvant chemotherapy or/and neoadjuvant chemotherapy will be needed even for early gastric cancer when lymph node metastasis is suspected.

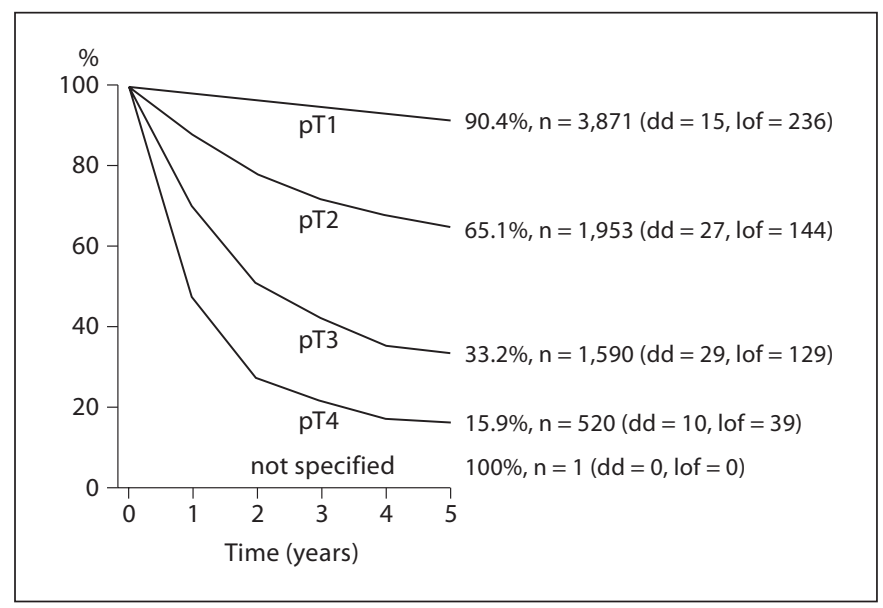

Fig. 2. Overall survival and depth of invasion. pT1 is early cancer. The 5-year survival following early gastric cancer is $>90 \%$. $\mathrm{dd}=$ Data defect; lof = loss of follow-up.

\section{References}

1 Japanese Society for Gastric Cancer: The General Rules for the Gastric Cancer Study. Tokyo, Kanehara, 2004.

-2 Maruyama K, Kaminishi M, Hayashi K; Japanese Gastric Cancer Association Registration Committee: Gastric cancer treated in 1991 in Japan: data analysis of nationwide registry. Gastric Cancer 2006;9:51-66.

3 Japan Gastric Cancer Association (eds): Guidelines for Gastric Cancer Treatment, ed 1. Tokyo, Kanehara, 2001.

4 Japan Gastric Cancer Association (eds): Guidelines for Gastric Cancer Treatment, ed 2. Tokyo, Kanehara, 2004.

5 Ishikawa M, Kitayama J, Kaizaki S: Prospective randomized trial comparing Billroth I and Roux-en-Y procedures after distal gastrectomy for gastric carcinoma. World J Surg 2005;29:1415-1420.

-6 Adachi S, Inagawa S, Enomoto T: Subjective and functional results after total gastrectomy: prospective study for longterm compar- ison of reconstruction procedures. Gastric Cancer 2003;6:24-29.

7 Nomura E, Shinohara H, Mabuchi H: Postoperative evaluation of the jejunal pouch reconstruction following proximal and distal gastrectomy for cancer. Hepatogastroenterology 2004;51:1561-1566.

8 Maki T, Shiratori T, Hatafuku T, Sugawara $\mathrm{K}$ : Pylorus-preserving gastrectomy as an improved operation for gastric ulcer. Surgery 1967;61:838-845.

9 Hiki N, Kaminishi M: Pylorus-preserving gastrectomy in gastric cancer surgery-open and laparoscopic approaches. Langenbecks Arch Surg 2005;390:442-447.

10 Shibata C, Shiiba KI, Funayama Y: Outcomes after pylorus-preserving gastrectomy for early gastric cancer: a prospective multicenter trial. World J Surg 2004;28:857-861.

11 Hiki N, Shimoyama S, Yamaguchi H, Kubota K, Kaminishi M: Laparoscopy-assisted pylorus-preserving gastrectomy with quali- ty controlled lymph node dissection in gastric cancer operation. J Am Coll Surg 2006; 203:162-169.

12 Adachi Y, Shiraishi N, Kitano S: Modern treatment of early gastric cancer: review of the Japanese experience. Dig Surg 2002;19: 333-339.

13 Hiki N, Shimizu N, Yamaguchi H, Imamura K, Kami K, Kubota K, Kaminishi M: Manipulation of the small intestine as a cause of the increased inflammatory response after open compared with laparoscopic surgery. Br J Surg 2006;93:195-204.

14 Aikou T, Kitagawa Y, Kitajima M: Sentinel lymph node mapping with GI cancer. Cancer Metastasis Rev 2006;25:269-277.

15 Kitagawa Y, Kitajima M: Diagnostic validity of radio-guided sentinel node mapping for gastric cancer: a review of current status and future direction. Surg Technol Int 2006;15: $32-36$. 